\title{
AN APPROACH FOR ASSESSMENT OF WEAVING LENGTH FOR MID-BLOCK TRAFFIC OPERATIONS
}

\author{
Mayank Dubey ${ }^{1}$, Sewa Ram ${ }^{2}$, Pradeep Kumar Sarkar ${ }^{3}$ \\ ${ }^{1,2,3}$ School of Planning and Architecture, New Delhi, India
}

Received 22 June 2015; accepted 17 August 2015

\begin{abstract}
Weaving is the cause of disturbance in traffic stream, because weaving vehicles must resort to lane changes within the length of weaving section available on ground. This tends to reduce the throughput and results in bottleneck of road system. Since the vehicles don't get safe gaps in stream, forced gap acceptance lead to unsafe lane changing operation towards the end of weaving sections and result in building up of queue. Research on issues of weaving sections is important for traffic administration as well as for facility design, especially for enhancing the efficiency and safety of road system. This research is aimed at developing to provide a relationship between the stream speed and available weaving lengths at different Level of Service (LOS) further, another approach to assess the desired weaving length for given speed and LOS is suggested. As the conditions were actual and the data was collected without disturbing the prevailing conditions, therefore results were obtained for specific set of LOS and prevailing speeds on the case corridor.
\end{abstract}

Keywords: traffic stream, lane change, bottleneck, gaps, Level of Service (LOS), mid-block.

\section{Introduction}

Weaving is generally defined as the crossing of two flows in the same general direction without the aid of traffic control devices as described by HCM 2000. Such a weaving flow generates intense lane-changing activities, whose resulting conflict significantly reduces the capacity of a weaving area. While the types of weaving patterns depend on the geometric configuration of given weaving areas, the most common type of weaving happens at a ramp-weave section where the merging flow from an on-ramp needs to cross the mainline vehicles diverging to an exit ramp through an auxiliary lane. Understanding the behavior of weaving flows and developing a procedure to estimate the capacity of a weaving area is of critical importance in managing traffic congestion in freeways. At times we observe the major merging and diverging occur due to ramps, therefore this research can help in identifying the space between flyovers and access to the road.

\section{Literature Review}

Various studies in the field of capacity of weaving sections and capacity of ramps, including the first HCM 1950 has tried to relate the weaving volume and speed w.r.t. to capacity. Although capacity is discussed in detail by various research studies but their effect upon heterogeneous traffic capacity and behavior is missing. Safety, together with

${ }^{2}$ Corresponding author: s.ram@spa.ac.in 
capacity, speed, operational flexibility, cost, and level of service, constitute fundamental design criteria. Cirillio (1970) analyzed the effective length of weaving sections, acceleration lanes, and deceleration lanes for merging and diverging capacities. HCM 2000 defines weaving capacity as the maximum total weaving flow beyond which acceptable operations are unlikely to occur. The HCM further provides the density thresholds, determined with the estimated speeds for weaving and nonweaving flows for a given weaving zone, as the Level of Service (LOS) criteria. Most past research activities have focused on the improvement of the HCM methodologies by proposing specific definitions of weaving capacity and/or models to estimate speed and flow levels within a weaving zone. Alternative LOS evaluation criteria have also been proposed by some researchers. This chapter summarizes the major research results found in the literature. The definition of weaving capacity was addressed by very few groups of researchers. Wang et al. (1993) defined weaving capacity as:

- The maximum flow of vehicles that can travel at any point (within a lane) of roadway within a subject weaving area, and

- The maximum rate of lane changing (between two adjacent lanes) that can occur over any $250 \mathrm{ft}$ segment within the weaving area.

In the same study, the authors also proposed a procedure predicting flow rates at different locations within a weaving section based on prevailing traffic and geometric conditions. For this purpose, the authors developed a family of curves using empirical and simulated data to estimate spatial distributions of each traffic movement.

\section{The Weaving Process}

Weaving operations include a complex set of decisions and actions as stated in Special Report 209 (HCM 1985) which may be generalized in the following sequence:

- Gap search in the merging traffic,

- Reducing the speed differential with merging traffic,

- Lane changing,

- Speed adjustment.

The above set of operations gets repeated multiple times if the geometry and layout of weaving section demands for the same. Somewhat similar action is repeated for maneuvering in diverging part of weaving section which may be generalized in following sequence:

- Gap search in the diverging traffic,

- Reducing the speed differential with diverging traffic,

- Lane changing.

Hence it is understood that "merging is a function of traffic flow behavior characterized by gap acceptance while diverging is a function of lane changing and gap acceptance".

\section{Methodology}

For arterial roads, varying typology of at grade and ramp weaving was studied in National Capital Territory of Delhi. Most representative and frequently available type of weaving on arterial roads was selected to represent case studies. A weaving section with 3 lanes in each of tributary arms (merging arms), 3 lanes in weaving and 3 lanes in each of the distributary arms (diverging arms) was termed as 3-3--3--3-3 
type of section. For the sake of uniformity in data collection, weaving section case studies were selected with similar lane typology. The traffic flow behavior along the case studies was captured with the help of digital video camera mounted on tripod at suitable locations to capture the maximum road area. Foot over bridges, adjoining high rise buildings and traffic police canopies were used for the same.

The data was extracted into digital format and the statistical significance tests were carried out on the samples collected. With reference to the Greenshield's Flow model, the flow, density and speeds were studied and assessed with respect to the mid-block behavior. The drop in throughput and other variables was also quantified. With the help of position-speed curves and their respective equations, desired weaving lengths were also worked out.

\section{Case Study}

The primary survey was carried out with the help of digital camera across four weaving sections across ring road in Delhi. A single section was studied during morning, afternoon, evening, and night to accommodate different characteristics of road users. The footage was then decoded for the various flow indicators like speed, flow and density. The locations and geometric details of the case studies are presented in Fig. 1 and Table 1.

\section{Weaving Section on ITO Flyover , ring road. Lane configuration - 3-3---3--3-3}

3. Weaving Section from eastern avenue road to Ashram on ring road. Lane configuration 3-3----3--- $3-3$

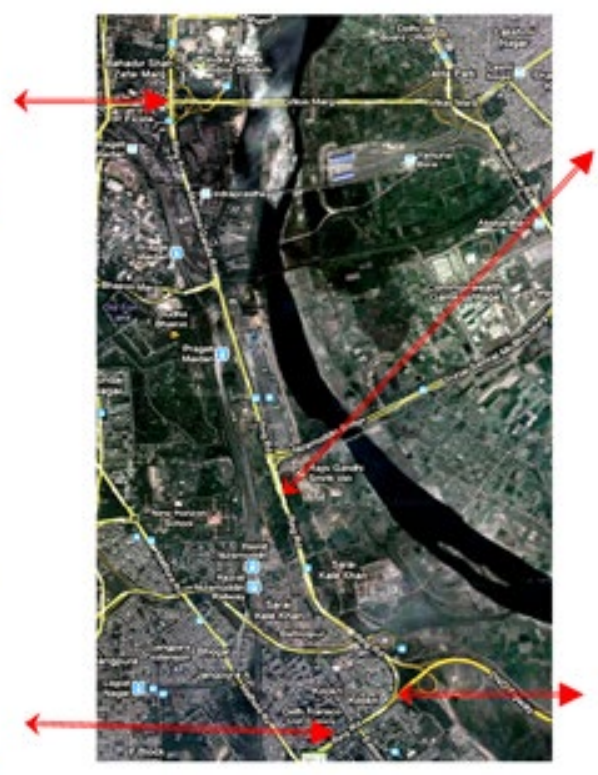

2. Weaving Section from millennium park to sarai kale khan on ring road. Laneconfiguration3-3----4----3-3

4. Weaving Section from DND to eastern avenue road on ring road. Laneconfiguration3-3---3--3-3

Fig. 1.

Location of Case Studies in Delhi

Source: Google Earth Satellite Image 


\section{Table 1}

Geometric Details of Case Studies

\begin{tabular}{|c|c|c|c|c|c|c|c|}
\hline Serial & Name & $\begin{array}{l}\text { Angle of } \\
\text { convergence } \\
\text { in degree }\end{array}$ & $\begin{array}{l}\text { Angle of } \\
\text { divergence } \\
\text { in degree } \\
\end{array}$ & $\begin{array}{l}\text { Length of } \\
\text { weaving in } \mathrm{km}\end{array}$ & $\begin{array}{l}\text { No of lanes } \\
\text { before weaving }\end{array}$ & $\begin{array}{l}\text { No of lanes } \\
\text { in weaving }\end{array}$ & Remark \\
\hline 1 & $\begin{array}{l}\text { ITO Flyover on } \\
\text { ring road }\end{array}$ & 15 & 15 & 0.17 & $3+3$ & 3 & Elevated \\
\hline 2 & $\begin{array}{l}\text { Between } \\
\text { Millennium Depot } \\
\text { and sarai Kale } \\
\text { khan }\end{array}$ & 5 & 5 & 0.36 & $3+3$ & 4 & $\begin{array}{l}\text { Heavy bus } \\
\text { weaving }\end{array}$ \\
\hline 3 & $\begin{array}{l}\text { Between DND } \\
\text { Flyway and } \\
\text { Eastern Avenue } \\
\text { Road }\end{array}$ & 10 & 20 & 0.5 & $3+3$ & 3 & $\begin{array}{l}\text { Kerb side } \\
\text { bus stop }\end{array}$ \\
\hline 4 & $\begin{array}{l}\text { Between Eastern } \\
\text { Avenue Road and } \\
\text { Ashram }\end{array}$ & 15 & 5 & 0.25 & $3+3$ & 3 & $\begin{array}{l}\text { Kerb side } \\
\text { bus stop }\end{array}$ \\
\hline
\end{tabular}

\section{Source: Primary Data Collection}

Further the data was also sub classified and collected into three sections within each case study as following:

- Before merging,

- In weaving,

- After diverging.
Following table provides the detail of primary data collected across the different case studies. The colour of cells represents traffic flow intensity increasing from green to brown.

Table 2

Flow Parameters w.r.t. Weaving Sections

\begin{tabular}{|c|c|c|c|c|c|c|c|c|}
\hline \multicolumn{3}{|c|}{ Before weaving } & \multicolumn{3}{|l|}{ In weaving } & \multicolumn{3}{|c|}{ After weaving } \\
\hline $\begin{array}{l}\text { Flow (q) } \\
\text { in vehicles } \\
\text { per hour }\end{array}$ & $\begin{array}{l}\text { Speed (v) } \\
\text { in km per } \\
\text { hour }\end{array}$ & \begin{tabular}{|l}
$\begin{array}{l}\text { Density } \\
(\mathrm{k}) \text { in }\end{array}$ \\
vehicles \\
per km
\end{tabular} & $\begin{array}{l}\text { Flow (q) } \\
\text { in vehicles } \\
\text { per hour }\end{array}$ & $\begin{array}{l}\text { Speed (v) } \\
\text { in km per } \\
\text { hour }\end{array}$ & $\begin{array}{l}\text { Density } \\
\text { (k) in } \\
\text { vehicles } \\
\text { per km }\end{array}$ & $\begin{array}{l}\text { Flow (q) } \\
\text { in vehicles } \\
\text { per hour }\end{array}$ & $\begin{array}{l}\text { Speed (v) } \\
\text { in } \mathrm{km} \text { per } \\
\text { hour }\end{array}$ & $\begin{array}{l}\text { Density } \\
\text { (k) in } \\
\text { vehicles } \\
\text { per km }\end{array}$ \\
\hline 1720 & 30 & 59 & \multirow{2}{*}{1223} & \multirow{2}{*}{25} & \multirow{2}{*}{79} & 1650 & 35 & 56 \\
\hline 1300 & 40 & 32 & & & & 1585 & 35 & 54 \\
\hline 930 & 45 & 36 & \multirow{2}{*}{828} & \multirow{2}{*}{30} & \multirow{2}{*}{46} & 1000 & 25 & 33 \\
\hline 730 & 45 & 20 & & & & 445 & 30 & 22 \\
\hline 440 & 40 & 10 & \multirow{2}{*}{755} & \multirow{2}{*}{55} & \multirow{2}{*}{71} & 485 & 40 & 15 \\
\hline 173 & 50 & 7 & & & & 268 & 40 & 12 \\
\hline 1240 & 50 & 48 & \multirow{2}{*}{352} & \multirow{2}{*}{40} & \multirow{2}{*}{47} & 1195 & 50 & 42 \\
\hline 837 & 60 & 30 & & & & 742 & 60 & 24 \\
\hline 1167 & 60 & 40 & \multirow{2}{*}{1073} & \multirow{2}{*}{50} & \multirow{2}{*}{60} & 620 & 40 & 33 \\
\hline 1225 & 40 & 47 & & & & 748 & 40 & 27 \\
\hline 947 & 70 & 27 & \multirow{2}{*}{1103} & \multirow{2}{*}{40} & \multirow{2}{*}{53} & 1493 & 25 & 60 \\
\hline 830 & 50 & 40 & & & & 1307 & 25 & 53 \\
\hline 690 & 30 & 19 & \multirow{2}{*}{1015} & \multirow{2}{*}{25} & \multirow{2}{*}{47} & 1055 & 35 & 40 \\
\hline 765 & 40 & 29 & & & & 1005 & 35 & 52 \\
\hline 1493 & 45 & 53 & \multirow{2}{*}{983} & \multirow{2}{*}{30} & \multirow{2}{*}{73} & 1128 & 25 & 47 \\
\hline 1307 & 45 & 23 & & & & 1083 & 30 & 50 \\
\hline
\end{tabular}

Source: Primary Data Collection 


\section{Delay Behavior in Weaving Section}

To provide a design benchmark for weaving section, it is necessary to quantify the Level of Service. As compared to mid-block section, weaving sections have inbuilt delay for the purpose of gap acceptance and lane changing behavior. This is stated as geometric delay. But it is observed that due to following reasons, stop delay goes on getting multiplied manifolds:

- Insufficient length of weaving section,

- Reduced number of lanes as compared to preceding mid-blocks. (Although reduced no. of lanes is good for reducing speed of stream and hence helps in accepting gap),

- Different weaving ratio and volume ratio,

- Different vehicle composition,

- Side friction.

Effect of weaving can easily be identified with the speed-flow-density curves developed during, before, in and after weaving. It is observed that flow gets decreased by an amount of $40 \%$ to $30 \%$ while maximum speed undergoes a decrease of up to $50 \%$. The maneuver of vehicle during the weaving results in gradual formation of bottlenecks for traffic operations, as shown in Fig. 2.

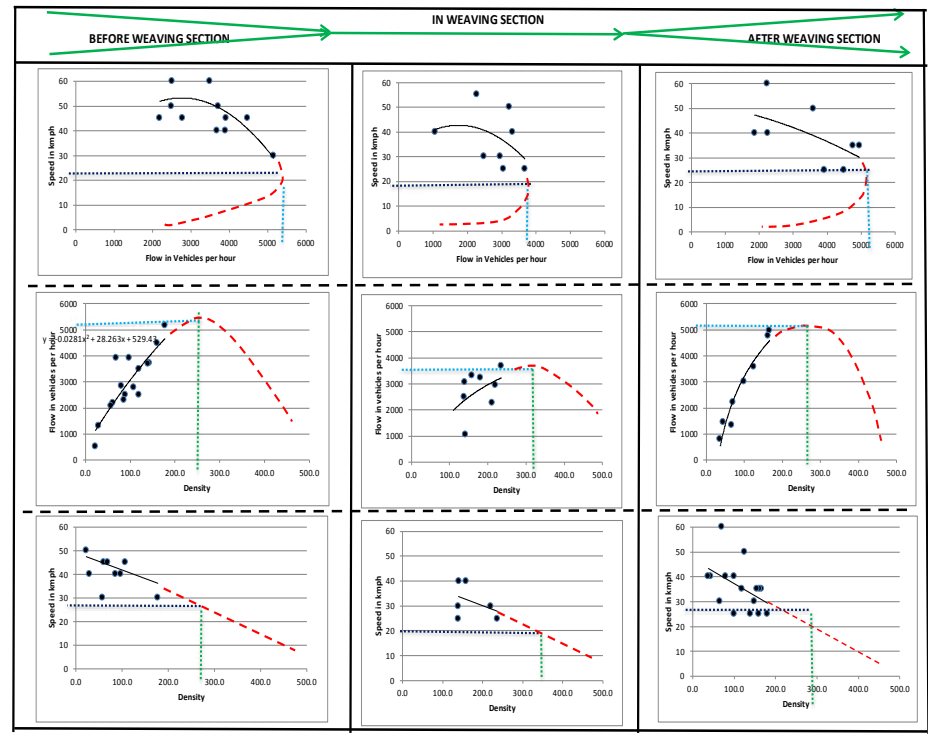

Fig. 2.

Traffic Flow Behavior in and around Weaving Section

Although most of the conditions plotted pertained to unsaturated or first half of the Greenshield's model but the curve has been developed assuming the theoretical traces of the relationship. The trajectory of mid-block and weaving sections was traced along with the field results and the delay hypothesis regarding the behavior with respect to delay of vehicular traffic at weaving sections is presented in Fig. 3. 


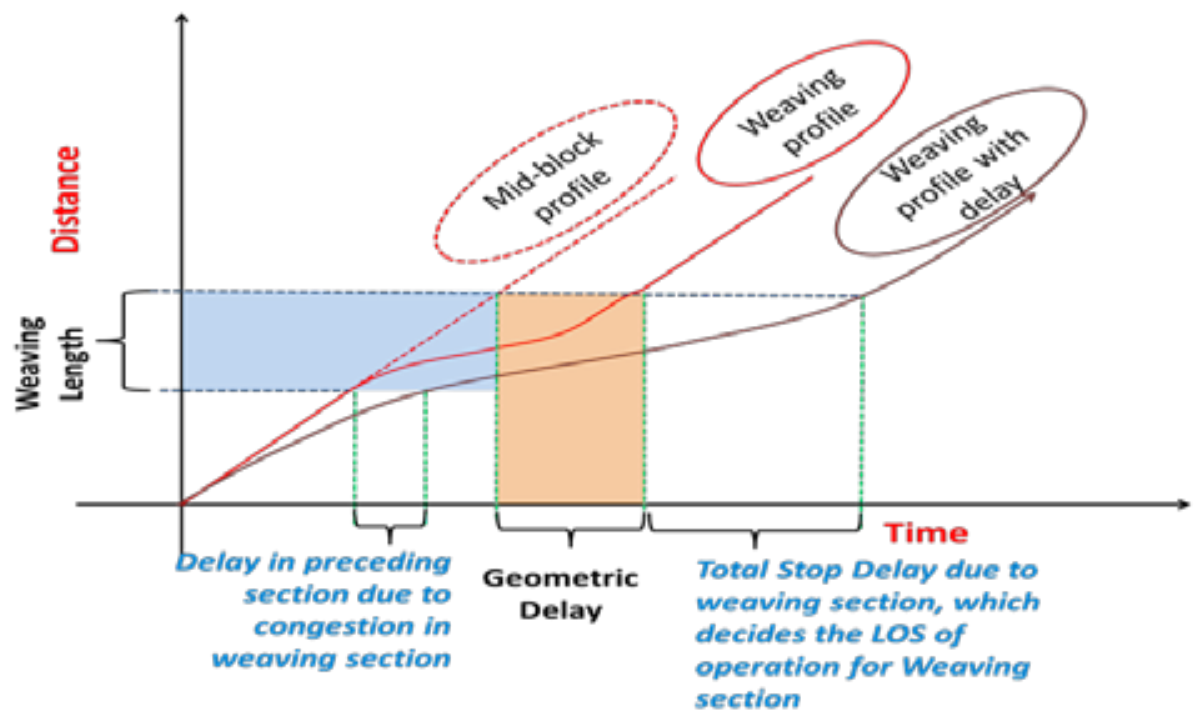

Fig. 3.

Conceptualized Delay Behavior Associated to Weaving Section

\section{Model Formulation}

Before development of model relating to the determination of weaving capacity of midblock, an attempt has been made to evolve the Level of Service (LOS) based on the traffic data collected along the different lanes of weaving section. The speed of vehicular traffic as against various magnitude of traffic flow has been recorded and plotted as a curve for different length of weaving section. It may be further mentioned that the LOS as defined by Indian Road Congress (I.R.C.) for various speed condition and traffic volume by capacity ratio (V/C ratio) as laid down in the code (IRC, 1990) was used while plotting particular volume against speed of vehicular traffic in weaving section. Table 3 presents the criterion for LOS.

Table 3

LOS Criterion for Traffic Flow

\begin{tabular}{|l|l|l|l|l|}
\hline Seri al & LOS & V/C Ratio\# & \% free flow speed for vehicular flow & $\begin{array}{l}\text { Threshold flow in veh/lane/hour for } \\
\text { corresponding LOS }\end{array}$ \\
\hline 1 & A & $0-0.3$ & $90 \%$ & 514 \\
\hline 2 & B & $0.3-0.5$ & $70 \%$ & 857 \\
\hline 3 & C & $0.5-0.7$ & $50 \%$ & 1200 \\
\hline 4 & D & $0.7-0.9$ & $40 \%$ & 1543 \\
\hline 5 & E & $0.9-1.0$ & $33 \%$ & $1714^{\wedge}$ \\
\hline 6 & F & - & Forced Flow/Breakdown & - \\
\hline
\end{tabular}

\# - Volume by capacity ratio as derived from \% free flow speed for vehicular traffic as laid down in IRC-106:1990

$\wedge$ - Maximum flow observed along case sections 
LOS was quantified from the flow and capacity variable for different dataset. For example, LOS B corresponds to $\mathrm{V} / \mathrm{C}$ ratio of $0.3-0.5$, therefore any flow between 514-857 vehicles/lane/hour gets classified as LOS B. The capacity assumed for calculating V/C is 1700 vehicles/lane/ hour as this was the maximum flow mostly observed across the dataset. According to different case capacities of Life-Cycle Cost Analysis Procedures Manual published by California Department of Transportation (LCCAPM, 2013), per lane capacities are in the range of 1800-1600 vehicles per lane per hour, which is in accordance to the results achieved.

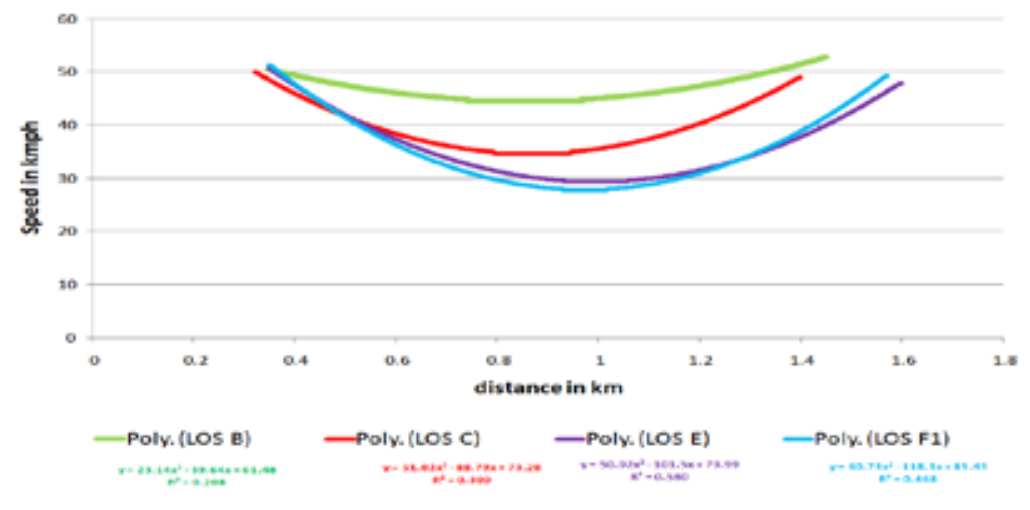

Fig. 4.

LOS Wise Speed and Weaving Length Relationship

Therefore, a number of points were generated based upon above method and Fig. 4 represents the graph plotted between weaving length as independent variable and vehicular flow speed as dependent variable for various LOS which was derived from $\mathrm{V} / \mathrm{C}$ ratio, as referred in Table 3. Plotting of the data between speed of vehicular traffic and $\mathrm{V} / \mathrm{C}$ ratio for given weaving length emerged in the form of 4 curves, each corresponding to a particular LOS. Due to nature and magnitude of traffic flow observed along the weaving sections, LOS A and LOS D could not be plotted for flow conditions.
These curves were finally translated in the form of quadratic equation, as presented in Table 4 which is nothing but various weaving distances in $\mathrm{km}$ for various LOS respective value for LOS A and LOS D was interpolated from the trend data available for other LOS. The respective equations of different LOS were plugged with varying speeds to calculate the theoretical weaving lengths. Since the prevailing speeds were consistently up to 50 $\mathrm{kmph}$, therefore for the LOS F (the extreme condition) figures for weaving length were extrapolated by the trendline for higher speeds of 60 and $70 \mathrm{kmph}$. 


\section{Table 4}

Calculated Weaving Lengths for Corresponding Speeds and LOS

\begin{tabular}{|l|l|l|l|l|l|l|l|l|l|}
\hline & \multirow{2}{*}{} & \multirow{2}{*}{ Flow } & \multirow{2}{*}{ Equation } & \multicolumn{6}{l}{ Weaving distance in $\mathrm{km}$ at given speeds in $\mathrm{kmph}$} \\
\cline { 4 - 11 } & & & 70 & 60 & 50 & 40 & 30 & 20 & 10 \\
\hline LOS A & 514 & --- & 2.44 & 1.67 & 0.90 & 0.13 & & & \\
\hline LOS B & 857 & $23.14 \mathrm{X}-16.49 \mathrm{X}+47.44$ & 2.44 & 1.67 & 0.97 & 0.45 & & & \\
\hline LOS C & 1200 & $51.02 \mathrm{X}-37.76 \mathrm{X}+41.64$ & 2.44 & 1.67 & 1.05 & 0.76 & 0.45 & & \\
\hline LOS D & 1543 & -- & 2.44 & 1.67 & 1.12 & 0.90 & 0.51 & 0.14 & \\
\hline LOS E & 1714 & $50.922-50.6 \mathrm{X}+41.96$ & 2.44 & 1.67 & 1.27 & 1.02 & 0.77 & 0.51 & 0.25 \\
\hline LOS F & 2091 & $60.73 \mathrm{X}-57.65 \mathrm{X}+41.42$ & 2.44 & 1.67 & 1.37 & 1.14 & 1.03 & 0.91 & 0.80 \\
\hline
\end{tabular}

Based on the field observation and subsequent analysis of data w.r.t. the speed-flow relationship at weaving section, a generic model has been attempted for weaving length against speed for various LOS. Fig. 5 represents the model.

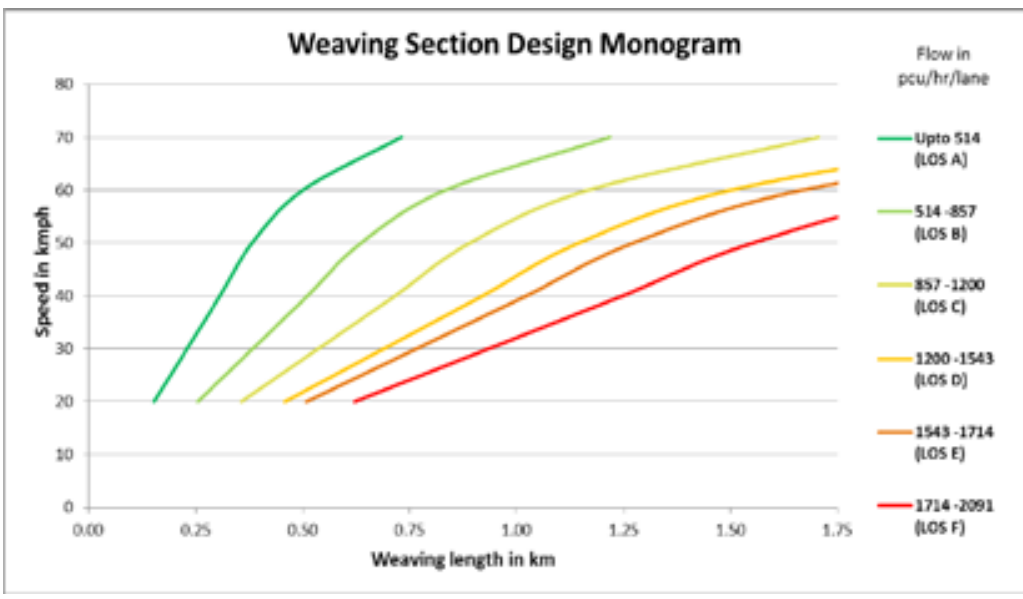

Fig. 5.

Desired Weaving Length w.r.t. Various Speeds and LOS

It should be noted that the curves towards better LOS are not merely a straight line curve but can be assumed to a group of curves. This was done intentionally so that the fitted curve doesn't deviate significantly from actual ground points and calculated points. It can be seen from the figure that at a given speed and LOS, say $50 \mathrm{kmph}$ and LOS $\mathrm{A}$, the desired weaving provision is to be provided for a length of $375 \mathrm{~m}$. Similar interpretations could be made for other LOS and speeds.

\section{Conclusion}

The method adopted to assess the capacity and LOS for the given weaving lengths helps in identifying the performance of 
other weaving sections in heterogeneous traffic conditions. Keeping in view the indepth analysis of traffic flow behavior in the weaving section, the study is conclusive with the following postulates:

- The study would provide significant impetus on working out traffic management schemes based upon the traffic behavior in weaving section. The traffic managers can take decisions upon the required number of lanes and length of weaving sections so as to maintain the desired LOS for ever increasing traffic flow.

- Further, the study also provides an insight relating to evaluation of weaving section under various traffic flow conditions. The generic model for weaving length and speed for different LOS would provide guidelines to design weaving sections on arterial roads.

The weaving lengths are calculated w.r.t. the prevailing mixed traffic conditions along the existing typology of weaving and weaving ratio. Specific research w.r.t. homogeneous and heterogeneous traffic along with varying weaving ratio and volume can be attempted.

\section{References}

Cirillo, J.A. 1970. The relationship of accidents to length of speed-change lanes and weaving areas on Interstate highways. Highway Research Record 312.

Highway Capacity Manual. 1985. Special Report 209, Highway Research Board.

Highway Capacity Manual. 1950. Highway Research Board.

Highway Capacity Manual. 2000 . Transportation Research Board.

IRC: 106. 1990. Guidelines for capacity of urban roads in plain areas.

Life-Cycle Cost Analysis Procedures Manual. 2013. California, California Department of Transportation.

Wang, M.; Cassidy, M.; Chan, P.; May, A. 1993. Evaluating the Capacity of Freeway Weaving Sections, Journal of Transportation Engineering. DOI: http://dx.doi.org/10.1061/(ASCE)0733947X(1993)119:3(360), 119(3): 360-384. 